\title{
Title:
}

\section{Impact of the COVID-19 lockdown on liver transplant recipients. A single center observational study}

\section{Authors:}

Antonio Cuadrado, Luis M Gaite, Aitor Odriozola, Rosario Oloriz, Sara Herrera, José I Fortea, Lidia Amigo, Edward J. Anderson, Jesús A. Artal, Javier Crespo, Emilio Fábrega

DOI: $10.17235 /$ reed.2021.8173/2021

Link: PubMed (Epub ahead of print)

Please cite this article as:

Cuadrado Antonio, Gaite Luis M, Odriozola Aitor, Oloriz Rosario, Herrera Sara, Fortea José I, Amigo Lidia, Anderson Edward J., Artal Jesús A., Crespo Javier, Fábrega Emilio. Impact of the COVID-19 lockdown on liver transplant recipients. A single center observational study . Rev Esp Enferm Dig 2021. doi: 10.17235/reed.2021.8173/2021.

This is a PDF file of an unedited manuscript that has been accepted for publication. As a service to our customers we are providing this early version of the manuscript. The manuscript will undergo copyediting, typesetting, and review of the resulting proof before it is published in its final form. Please note that during the production process errors may be discovered which could affect the content, and all legal disclaimers that apply to the journal pertain. 


\section{OR 8173}

Impact of the COVID-19 lockdown on liver transplant recipients. A single center observational study

Antonio Cuadrado ${ }^{1,2}$, Luis M. Gaite ${ }^{2,3}$, Aitor Odriozola ${ }^{1,2}$, Rosario Oloriz ${ }^{1,2}$, Sara Herrera ${ }^{2,3}$, José I Fortea ${ }^{1,2}$, Lidia Amigo ${ }^{1,2}$, Edward J. Anderson ${ }^{4}$, Jesús A. Artal2,3, Javier Crespo $^{1,2}$ and Emilio Fábrega ${ }^{1,2}$

Departments of ${ }^{1}$ Gastroenterology and Hepatology, ${ }^{3}$ Psychiatry and ${ }^{4}$ Surgery. Hospital Universitario Marqués de Valdecilla. Facultad de Medicina. Universidad de Cantabria. Santander, Cantabria. Spain. ${ }^{2}$ Valdecilla Biomedical Research Institute (IDIVAL). Santander, Cantabria. Spain.

Received: $28 / 06 / 2020$

Accepted: 01/08/2021

Correspondence: Antonio Cuadrado. Department of Gastroenterology and Hepatology. Hospital Universitario Marqués de Valdecilla. Facultad de Medicina. Universidad de Cantabria. Av. de Valdecilla, s/n. 39008 Santander, Cantabria. Spain e-mail: antonio.cuadrado@scsalud.es Jesús A. Artal. Department of Psychiatry. Hospital Universitario Marqués de Valdecilla. Facultad de Medicina. Universidad de Cantabria. Av. de Valdecilla, s/n. 39008 Santander, Cantabria. Spain

e-mail: jesusangel.artal@scsalud.es

\section{AUTHOR CONTRIBUTIONS}

All authors contributed to and have approved the final manuscript.

All authors had access to the study data and critically reviewed, revised and approved the final manuscript. All the authors fulfil the four ICMJE authorship criteria (substantial contributions to conception or design of the work, or the acquisition, analysis, or interpretation of data for the work; drafting of the work or revising it). 
A.C., R.O., L.M.G., S.H., J.A.A., J.C. and E.F. participated in research design; A.C., A.O., L.M.G, SH., R.O., J.I.F., L.A., E.J.A., J.A.A., J.C. and E.F. participated in the performance of the research; A.C., A.O., L.M.G, S.H., R.O., J.I.F., L.A., E.J.A., J.A.A., J.C. and E.F. participated in the writing of the paper; A.C., A.O., L.M.G., S.H., J.I.F., J.A.A., J.C. and E.F. participated in data analysis

Funding: this research did not receive any specific grant from funding agencies in the public, commercial, or not-for-profit sectors.

Conflict of interest: the authors declare no conflict of interest.

Acknowledgments: we wish to express our gratitude and respect to the patients and parents, for sharing their experiences with us.

\section{ABSTRACT}

Background: the impact of the COVID-19 outbreak and lockdown on liver transplant (LT) patients remains unknown. The aim of this cross-sectional study was to assess the consequences of the COVID-19 pandemic on the physical and mental health of LT patients during the lockdown period.

Methods: a web-based questionnaire was emailed to 238 LT patients undergoing regular follow-up at our unit between August and October 2020. This pseudonymized survey explored demographic and lifestyle variables (i.e., eating and physical habits), disruptions in routine medical care, different dimensions of mental health, COVID-19related mood and coping (worries/anxiety, depression, insomnia, fear of COVID, resilience, etc.) and health perception using different validated instruments.

Results: altogether, $48.7 \%$ (116 of 238) LT recipients accepted to participate in the study, 104 of whom gave their consent to publish the data. The median age was 63 years. Up to $39.4 \%$ presented worrying scores indicating moderate/severe generalized anxiety disorder (GAD), whereas $25.5 \%$ exhibited moderate/severe insomnia and only $10.5 \%$ moderate/severe depression. Forty patients (38.5\%) gained weight, $24 \%$ experienced a worsening in their eating habits and $63.4 \%$ referred to practicing less or 
much less exercise during the lockdown. Only $25 \%$ perceived a worsening in the control of their chronic comorbidities. Missed medical appointments (0.9\%) or poor adherence to therapy (1.9\%) were exceptional.

Conclusions: COVID-19 lockdown has negatively impacted the mental and physical health of LT patients. Long-term consequences remain unclear.

Keywords: COVID-19. SARS-CoV-2. Liver transplant. Mental health. Anxiety. Quality of life.

\section{INTRODUCTION}

On January $30^{\text {th }}, 2020$, the World Health Organization (WHO) declared the global 2019 coronavirus disease outbreak (COVID-19) a public health emergency (1). The Spanish Government declared a lockdown on March $14^{\text {th }}$ as a result of the pandemic that lasted almost two months (2). As a result, the Spanish population was placed in social isolation with permission to leave the house limited to buying food or medicine. These measures greatly disrupted people's lives and had implications on health and wellbeing in the general population (3).

Previous studies on subjects who had been quarantined for acute infectious diseases, like severe acute respiratory syndrome (SARS) or Middle East respiratory syndrome (MERS), reported a high prevalence of symptoms of psychological distress $(4,5)$. These included anxiety, depression, insomnia and fear of getting sick or dying. Fear is an adaptive defense mechanism that is fundamental for survival and involves several biological processes of preparation for a response to potentially threatening events. However, when it is disproportionate, as in a pandemic, it becomes harmful. Thus, it has been associated with increasing degrees of anxiety, stress and insomnia in healthy individuals and with more intense symptoms in those with pre-existing psychiatric disorders (6).

There are indications of increased levels of post-traumatic stress disorder and depression following SARS-CoV-2 infection (7). Quarantine and the isolation associated with the pandemic are additional risk factors for psychological impact. Other reported consequences of quarantine stress are the onset and continuation of tobacco 
consumption and alcohol abuse (8) and a change in lifestyle and eating habits leading to an unhealthy diet $(6,7)$. All of them carry an increased risk of obesity, diabetes and cardiovascular disease (CVD).

However, little is known about the long-term impact of the COVID-19 lockdown on the global health (physical and mental) of liver transplant (LT) patients. The disruption of routine medical care is especially problematic for patients with chronic conditions that require regular follow-up such as LT recipients. They require continuous medical surveillance due to polypharmacy, comorbidities and the risk of allograft rejection. Therefore, the aim of the present study was to evaluate the impact of the COVID-19 lockdown in Spain on the overall health of LT recipients.

\section{MATERIAL AND METHODS}

\section{Study design and participants}

A web-based cross-sectional pseudonymized survey was performed based on SurveyMonkey $^{\mathrm{TM}}$. This study was approved on July $19^{\text {th }}, 2020$ by the Ethics Committee of Cantabria (act 19/2020).

The on-line survey was developed by members of the LT Unit and Psychiatric Department of the University Hospital Marqués de Valdecilla (Spain). It covered five sections about health habits and physical and mental repercussions during the period of home confinement established by the Spanish authorities from March $15^{\text {th }}$ to May $4^{\text {th }}, 2020$ (Fig. 1). The on-line survey was piloted with the research team prior to being sent to all LT patients undergoing regular follow-up at the LT unit of our hospital. Exclusion criteria were the patient's refusal to participate, active cancer, an estimated life expectancy of less than one year, severe psychiatric disease and inability to participate due to either technological barriers or impossibility to attend to the outpatient clinic to complete the survey. All participants were requested to sign the informed consent either online or at the hospital. The data were collected electronically between August and October 2020.

\section{Survey sections}


The first section included sociodemographic data (Table 1) and medical comorbidities. The second section comprised items related to lifestyle, sources of information about COVID-19 and self-care during the lockdown. Participants were also required to answer different questions about weight gain and eating and exercise habits.

In the third section, participants were invited to fill out different validated questionnaires on reactions and coping strategies to the COVID-19 pandemic and other general questionnaires to evaluate mental health. The Fear of COVID-19 Scale was used to measure the fear of suffering COVID-19. This scale ranges from 7 to 35 points, the latter indicating a maximum level of fear (9). Pathological worry was addressed using the Spanish abbreviated version of the Penn State Worry Questionnaire (PSWQ-11), the gold standard measure of unspecific worry that characterizes generalized anxiety disorder (GAD) $(10,11)$. On this scale, the highest possible score indicating a state of maximal concern is 55 and the cutoff points to identify a moderate and severe GAD are 33 and 38 points, respectively. The ability to recover from stress was evaluated using the Spanish version of the brief resilience scale (BRS-6) (12,13). The BRS-6 was coded as low (1.00-2.99), normal (3.00-4.30) and high (4.31-5.00). Insomnia severity was evaluated using the Spanish version of the seven-item insomnia severity index (ISI), the cutoffs for moderate and severe insomnia were 15 and 22 points, respectively (14). The Spanish version of the List of Threatening Experiences (LTE) was used to assess recent stressful events, which is a subset of 12 life event categories with considerable long-term contextual threat (LTE-12) $(15,16)$. Finally, depression was evaluated using the patient health questionnaire 9 (PHQ-9) (17). The PHQ-9 classed the level of depression severity as minimal (0-4), mild (5-9), moderate (10-14) and severe ( $\geq 15)$.

The fourth section was designed to identify self-reported changes in LT treatment and adherence to treatment, and to evaluate the perception of health surveillance during the lockdown. Participants were also asked if they had experienced a SARS-CoV-2 infection. In the fifth section, the patients were asked about their health-related quality of life using the EuroQol-5D-3L. A descriptive evaluation of five dimensions (mobility, self-care, usual activities, pain/discomfort and anxiety/depression) was performed. Each dimension has three possible levels scored from 1 (no problems) to 3 
(extreme problems); a score of 1 in all the five items was considered as full health. In a second part, patients had to complete the EQ-5D visual analogue scale (VAS), a 0-100 scale where they were asked to indicate overall health perception, 0 being the worst and 100 the best imaginable health condition, respectively (18).

\section{Statistical analyses}

Quantitative variables were expressed as the mean (standard deviation) or median (range or interquartile range [IQR]), and qualitative variables as absolute values and proportions. Statistical analysis was performed with IBM SPSS Statistics v22.0 for Mac (IBM Corp., Armonk, NY).

\section{RESULTS}

Of 315 LT patients undergoing regular follow-up at our LT unit, 238 were eligible to participate in the study. One hundred and sixteen (48.8\%) accepted and completed the survey (Fig. 2). Finally, 104 LT participants gave their consent to publish the data. None of the participants reported current or past COVID-19 disease.

\section{Socio-demographic and medical characteristics of the participants}

The median age of the participants was 63 years (range $30-83$ ) with a median time since LT of 99 months (6-320) (Table 1). Overall, $75 \%$ of the patients were males, and most were of Spanish nationality (97\%). More than half of the participants $(53.8 \%)$ had basic studies and most participants (86.5\%) were confined at home and unemployed. Participant characteristics and comorbidities are shown in table 1.

\section{Lifestyle, information seeking on COVID-19 and self-care}

Most patients ( $75 \%$ ) acknowledged living with someone during the confinement and one quarter did not have a garden, terrace or outside access. The most frequent causes for going out during the COVID-19 lockdown were shopping (supermarket, pharmacy) and waste disposal (80\%). The majority of patients felt sufficiently informed about the coronavirus pandemic. 
The vast majority of patients $(90 \%)$ reported washing hands and wearing masks more frequently than before the COVID-19 lockdown. Only $7.7 \%$ required medical assistance or testing for SARS-CoV-2 infection, with no positive cases. Moreover, less than $1 \%$ of the patients started or increased their alcohol or tobacco consumption, and none started using other substances such as cannabis, cocaine or other drugs.

\section{Mental health, mood and coping during COVID-19 lockdown}

Participants showed intermediate levels of fear on the Fear of COVID-19 Scale (median 18; IQR: 7-28). When COVID-19-related worries were addressed using the Spanish version of the PSWQ-11, the median score was 30 (11-47). According to the PSWQ-11, $60.6 \%$ of the patients did not present GAD (95\% Cl: 50.5-69.9), whereas $18.1 \%$ (11.6-27.1) and $21.3 \%(14.2-30.6)$ had moderate and severe GAD, respectively. Most participants had no insomnia or only subclinical insomnia (74.5\%; 64.8-82.2) on the ISI scale. However, up to $23.4 \%$ (16.0-32.9) had moderate clinical insomnia and $2.1 \%$ (0.6-7.4) severe insomnia. Eleven participants (10.5\%; 6.0-17.9) reported at least a moderate degree of depression defined as a PHQ9 $\geq 10$, whereas only four patients (3.8\%; 1.5-9.5) had major depression (PHQ9 $\geq 15$ ). Finally, most participants suffered no additional stressful events $(60.6 \%$; $50.9-69.4)$ in the LTE scale, and showed normal or high levels of resilience (79.6\%; 70.3-86.5).

\section{Physical health, well-being and medical care}

Forty participants (38.5\%) experienced weight gain. Twenty-five patients (24\%) reported worsening eating habits (eating extra, more often, unhealthily or erratically) and $63.4 \%$ practiced less or much less physical activity than before.

A minority of patients (1\%) missed medical consultations because of fear of SARSCoV-2 infection, and most participants had their face-to-face consultations changed to telephone consultations (75\%). Missed medication doses or drug schedule changes were exceptional (1.9\%). Moreover, no patient reported problems in collecting their medication during the confinement. No patient experienced rejection or other liverrelated complications. Twenty-six patients ( $25 \%$ ) perceived the control of their chronic medical comorbidities as worse or much worse, while the remaining patients 
perceived the same control as before lockdown. Participants who perceived a poorer control attributed it to worse eating and exercise habits (42.3\%), higher levels of anxiety, fear or stress (37.5\%) and/or to greater difficulties in obtaining adequate medical assistance (20.2\%) during the COVID-19 lockdown.

\section{Health-related quality of life}

The proportion of patients in full health was $48.07 \%$ (50/104). Figure 3 shows the level of reported problems in each of the five dimensions of the EQ-5D-3L questionnaire. Although most of the patients did not present problems in the different dimensions evaluated, up to $30 \%$ of the patients presented moderate/high levels of pain/discomfort and anxiety/depression. The median EQ-5D-3L VAS score was 78 points (IQR: 21).

\section{DISCUSSION}

The COVID-19 confinement period resulted in poorer diet and physical exercise habits leading to poor weight control, and a perception of worse control of their medical conditions in up to $25 \%$ of the LT patients surveyed. Remarkably, up to $40 \%$ exhibited moderate or severe levels of anxiety and up to one quarter referred moderate or severe insomnia. However, high rates of resilience were detected.

Our LT population felt well informed about the development of the pandemic and also had intermediate levels of concern and fear of COVID-19 infection, as recently reported (19). There were no cases of infection in the study period. Health authorities during this period reported a mean and maximum incidence of 110 and 263 cases per 100,000 inhabitants, respectively. In contrast with previous studies $(8,19,20)$, most participants showed a high adherence to immunosuppressive and other prescribed drugs, with no changes in their tobacco or alcohol habits, likely related to the short period of confinement. Given the potential risk of infection in hospitals, most participants had their face-to-face consultations changed to telephone consultations soon after lockdown. As shown by other studies (21-23), this change seemed to have no impact on the medical surveillance of our LT recipients. 
Up to $39 \%$ of participants showed moderate or severe GAD, which had an impact on their perception of quality of life. Previous reports about COVID-19 and psychoemotional distress have also reported moderate and severe depressive or anxious symptoms in about one third of patients (24-29). The lower percentage of moderatesevere depression (10.5\%) in our study appears to correlate with the high degree of resilience shown by our patients. Indeed, only a few respondents reported a loss of confidence and interest in things or poorer decision making, all of which represent coping mechanisms to overcome a crisis. In line with previous reports, the most common symptoms of our patients were related to sleeping disorders $(30,31)$. Up to $72.3 \%$ of the patients showed some degree of insomnia during the lockdown, with $25 \%$ reporting moderate-severe insomnia. These changes are probably related to changes in sense of time, sedentary lifestyle, prolonged television viewing time and increased use of electronic devices.

Since the start of the lockdown, almost $40 \%$ of the patients reported weight gain mainly related to changes in eating habits and a reduction in physical activity. These changes in short periods of time can become permanent and lead to substantial weight gain (32). In fact, up to $40 \%$ of the patients who perceived poorer control of their chronic comorbidities attributed it to diet and exercise. Regardless of this, given their well-known association with deleterious health outcomes (33-35), our study highlights the need to implement strategies to further increase home-based physical activity and to encourage adherence to a healthy diet during periods of confinement.

Some of the limitations of our study are related to the cross-sectional design that evaluated a short period of time. The absence of baseline records for some of the instruments used, the single-center nature of the study and a possible selection bias related to low participation may also constitute certain limitations. However, the extraordinary nature of the situation makes the findings relevant to foresee and face similar situations in the future.

In conclusion, there is a negative impact of confinement on both physical and mental health of LT patients. It is likely that longer periods of confinement and observation may show a greater impact. Therefore, it is necessary to develop psychological and nutritional support measures and enhance physical exercise to minimize these 
negative effects.

\section{REFERENCES}

1. World Health Organization (WHO). Coronavirus disease (COVID-19) pandemic. Geneva: WHO; 2020. Accessed: December $1^{\text {st }}$, 2020. Available from: https://www.who.int

2. Real Decreto $463 / 2020$, de 14 de marzo, por el que se declara el estado de alarma para la gestión de la situación de crisis sanitaria ocasionada por el COVID-19. Accessed: December $1^{\text {st }}$ 2020. Available from: https://www.boe.es/boe/dias/2020/03/14/pdfs/BOE-A-2020-3692.pdf

3. Bao Y, Sun Y, Meng S, et al. 2019-nCoV epidemic: address mental health care to empower society. Lancet 2020;395(10224):e37-8. E-pub ahead of print. PMID 32043982. DOI: 10.1016/S0140-6736(20)30309-3

4. Brooks SK, Webster RK, Smith LE, et al. The psychological impact of quarantine and how to reduce it: rapid review of the evidence. Lancet 2020;395(10227):912-20. Epub ahead of print. PMID 32112714. DOI: 10.1016/S0140-6736(20)30460-8

5. Jeong H, Yim HW, Song YJ, et al. Mental health status of people isolated due to Middle East respiratory syndrome. Epidemiol Health 2016;38:e2016048. E-pub ahead of print. PMID 28196409. DOI: 10.4178/epih.e2016048

6. Shigemura J, Ursano RJ, Morganstein JC, et al. Public responses to the novel 2019 coronavirus (2019-nCoV) in Japan: mental health consequences and target populations. E-pub ahead of print. Psychiatry Clin Neurosci 2020;74(4):281-2. PMID 32034840. DOI: 10.1111/pcn.12988

7. Vindegaard N, Benros ME. COVID-19 pandemic and mental health consequences: systematic review of the current evidence. Brain Behav Immun 2020;89:531-42. E-pub ahead of print. PMID 32485289. DOI: 10.1016/j.bbi.2020.05.048

8. Clay JM, Parker MO. Alcohol use and misuse during the COVID-19 pandemic: a potential public health crisis? Lancet Public Health 2020;5(5):e259. E-pub ahead of print. PMID 32277874. DOI: 10.1016/S2468-2667(20)30088-8 
9. Ahorsu DK, Lin CY, Imani V, et al. The Fear of COVID-19 Scale: development and initial validation. Int J Ment Health Addict 2020;1-9. E-pub ahead of print. PMID 32226353. DOI: 10.1007/s11469-020-00270-8

10. Meyer TJ, Miller ML, Metzger RL, et al. Development and validation of the Penn State Worry Questionnaire. Behav Res Ther 1990;28(6):487-95. E-pub ahead of print. PMID 2076086. DOI: 10.1016/0005-7967(90)90135-6.

11. Sandín B, Chorot P, Valiente RM, et al. Validación española del cuestionario de preocupación PSWQ: estructura factorial y propiedades psicométricas. Rev Psicopatol Psicol Clin 2009;14:107-22. DOI: 10.5944/rppc.vol.14.num.2.2009.4070

12. Rodríguez-Rey R, Alonso-Tapia J, Hernansaiz-Garrido H. Reliability and validity of the Brief Resilience Scale (BRS) Spanish Version. Psychol Assess 2016;28(5):e101-10. E-pub ahead of print. PMID 26502199. DOI: 10.1037/pas0000191

13. Smith BW, Dalen J, Wiggins $\mathrm{K}$, et al. The brief resilience scale: assessing the ability to bounce back. Int J Behav Med 2008;15(3):194-200. E-pub ahead of print. PMID 18696313. DOI: 10.1080/10705500802222972

14. Fernández-Mendoza J, Rodríguez-Muñoz A, Vela-Bueno A, et al. The Spanish version of the Insomnia Severity Index: a confirmatory factor analysis. Sleep Med 2012;13(2):207-10. E-pub ahead of print. PMID 22172961. DOI: 10.1016/j.sleep.2011.06.019

15. Brugha $T$, Bebbington $P$, Tennant $C$, et al. The list of threatening experiences: $a$ subset of 12 life event categories with considerable long-term contextual threat. Psychol Med 1985;15(1):189-94. E-pub ahead of print. PMID 3991833. DOI: $10.1017 / \mathrm{s} 003329170002105 x$

16. Motrico E, Moreno-Kustner B, Luna JD, et al. Psychometric properties of the List of Threatening Experiences (LTE) and its association with psychosocial factors and mental disorders according to different scoring methods. J Affect Disord 2013;150(3):931-40. E-pub ahead of print. PMID 23726778. DOI: 10.1016/j.jad.2013.05.017

17. Kroenke K, Spitzer RL, Williams JB. The PHQ-9: validity of a brief depression severity measure. J Gen Intern Med 2001;16(9):606-13. E-pub ahead of print. PMID 11556941. DOI: 10.1046/j.1525-1497.2001.016009606.x 
18. Brooks R. EuroQol: the current state of play. Health Policy 1996;37(1):53-72. Epub ahead of print. PMID 10158943. DOI: 10.1016/0168-8510(96)00822-6

19. Reuken PA, Rauchfuss F, Albers S, et al. Between fear and courage: attitudes, beliefs, and behavior of liver transplantation recipients and waiting list candidates during the COVID-19 pandemic. Am J Transplant 2020;20(11):3042-50. E-pub ahead of print. PMID 32515125. DOI: 10.1111/ajt.16118

20. Conway TL, Vickers RR Jr, Ward HW, et al. Occupational stress and variation in cigarette, coffee, and alcohol consumption. J Health Soc Behav 1981;22(2):155-65. Epub ahead of print. PMID 7240714. DOI: 10.2307/2136291

21. Hong $\mathrm{Z}$, Li N, Li D, et al. Telemedicine during the COVID-19 pandemic: experiences from Western China. J Med Internet Res 2020;22(5):e19577. E-pub ahead of print. PMID 32349962. DOI: 10.2196/19577

22. Mills EC, Savage E, Lieder J, et al. Telemedicine and the COVID-19 pandemic: are we ready to go live? Adv Skin Wound Care 2020;33(8):410-7. E-pub ahead of print. PMID 32701252. DOI: 10.1097/01.ASW.0000669916.01793.93

23. Patel S, Douglas-Moore J. A reflection on an adapted approach from face-toface to telephone consultations in our Urology Outpatient Department during the COVID-19 pandemic - A pathway for change to future practice? BJU Int 2020;126(3):339-41. E-pub ahead of print. PMID 32469096. DOI: 10.1111/bju.15119

24. Cellini N, Canale N, Mioni G, et al. Changes in sleep pattern, sense of time and digital media use during COVID-19 lockdown in Italy. J Sleep Res 2020;29(4):e13074. Epub ahead of print. PMID 32410272. DOI: 10.1111/jsr.13074

25. Pierce $M$, Hope $H$, Ford $T$, et al. Mental health before and during the COVID-19 pandemic: a longitudinal probability sample survey of the UK population. Lancet Psychiatry 2020;7(10):883-92. E-pub ahead of print. PMID 32707037. DOI: 10.1016/S2215-0366(20)30308-4

26. Rossi R, Socci V, Talevi D, et al. COVID-19 pandemic and lockdown measures impact on mental health among the general population in Italy. Front Psychiatry 2020;11:790. E-pub ahead of print. PMID 32848952. DOI: 10.3389/fpsyt.2020.00790

27. Salari N, Hosseinian-Far A, Jalali R, et al. Prevalence of stress, anxiety, depression among the general population during the COVID-19 pandemic: a systematic 
review and meta-analysis. Global Health 2020;16(1):57. E-pub ahead of print. PMID 32631403. DOI: 10.1186/s12992-020-00589-w

28. Xiao $H$, Zhang $Y$, Kong $D$, et al. The effects of social support on sleep quality of medical staff treating patients with coronavirus disease 2019 (COVID-19) in January and February 2020 in China. Med Sci Monit 2020;26:e923549. E-pub ahead of print. PMID 32132521. DOI: 10.12659/MSM.923549

29. Xiao $H$, Zhang $Y$, Kong $D$, et al. Social capital and sleep quality in individuals who self-isolated for 14 days during the coronavirus disease 2019 (COVID-19) outbreak in January 2020 in China. Med Sci Monit 2020;26:e923921. E-pub ahead of print. PMID 32194290. DOI: 10.12659/MSM.923921

30. Altena E, Baglioni C, Espie CA, et al. Dealing with sleep problems during home confinement due to the COVID-19 outbreak: practical recommendations from a task force of the European CBT-I Academy. J Sleep Res 2020;29(4):e13052. E-pub ahead of print. PMID 32246787. DOI: 10.1111/jsr.13052

31. Voitsidis P, Gliatas I, Bairachtari V, et al. Insomnia during the COVID-19 pandemic in a Greek population. Psychiatry Res 2020;289:113076. E-pub ahead of print. PMID 33242799. DOI: 10.1016/j.psychres.2020.113076

32. Schoeller DA. The effect of holiday weight gain on body weight. Physiol Behav 2014;134:66-9 E-pub ahead of print. PMID 24662697. DOI: 10.1016/j.physbeh.2014.03.018

33. Lee IM, Shiroma EJ, Lobelo F, et al. Effect of physical inactivity on major noncommunicable diseases worldwide: an analysis of burden of disease and life expectancy. Lancet 2012;380(9838):219-29. E-pub ahead of print. PMID 22818936. DOI: 10.1016/S0140-6736(12)61031-9

34. Poelman MP, Gillebaart M, Schlinkert C, et al. Eating behavior and food purchases during the COVID-19 lockdown: a cross-sectional study among adults in the Netherlands. Appetite 2021;157:105002. E-pub ahead of print. PMID 33068668. DOI: 10.1016/j.appet.2020.105002

35. Saqib MAN, Siddiqui S, Qasim M, et al. Effect of COVID-19 lockdown on patients with chronic diseases. Diabetes Metab Syndr 2020;14(6):1621-3. E-pub ahead of print. PMID 32889403. DOI: 10.1016/j.dsx.2020.08.028 
Table 1. General characteristics of the study population

\begin{tabular}{|c|c|c|c|}
\hline Variable & $(n=104)$ & Variable & $(n=104)$ \\
\hline Socio-demographic & & Medical history & \\
\hline Age (years) & $63(30-83)$ & LT-related & \\
\hline Gender (men) & $78(75)$ & Etiology of liver disease & \\
\hline Spanish nationality & $101(97.1)$ & Alcohol & $45(43.3)$ \\
\hline Educational level & & Hepatitis C & 28 (26.9) \\
\hline Primary Education & $31(29.8)$ & Others & $31(29.8)$ \\
\hline Secondary Education & $25(24)$ & LT indication & \\
\hline Advanced Vocational Training & $18(17.4)$ & Decomp. cirrhosis & $47(45.2)$ \\
\hline University degree & $30(28.8)$ & $\mathrm{HCC}$ & $42(40.4)$ \\
\hline Marital status & & Others & $15(14.4)$ \\
\hline Married/living with a partner & $78(75)$ & Months from LT & $99(6-320)$ \\
\hline Single & $9(8.7)$ & Comorbidities & \\
\hline Separated or divorced & $7(6.8)$ & Diabetes & $56(53.8)$ \\
\hline Widowed & $10(9.5)$ & Hypertension & $62(59.6)$ \\
\hline Occupation & & CVD & $34(32.7)$ \\
\hline Employed & $14(13.5)$ & Bronchopulmonary & $34(32.7)$ \\
\hline Working at home & $8(7.7)$ & Obesity & $43(41.3)$ \\
\hline Working out & $6(5.8)$ & CKD & $41(39.4)$ \\
\hline Unemployed/looking & $18(17.3)$ & & \\
\hline Retired & $72(69.2)$ & & \\
\hline Studying & $0(0)$ & & \\
\hline \multicolumn{4}{|l|}{ Place of residence } \\
\hline Rural & $67(64.4)$ & & \\
\hline Urban & 37 (35.6) & & \\
\hline
\end{tabular}

Qualitative variables are expressed as number and percentage (n; \%); quantitative variables are expressed as median and range (median; range). LT: liver transplant; HCC: hepatocellular carcinoma; CVD: cardiovascular disease; CKD: chronic kidney disease. 


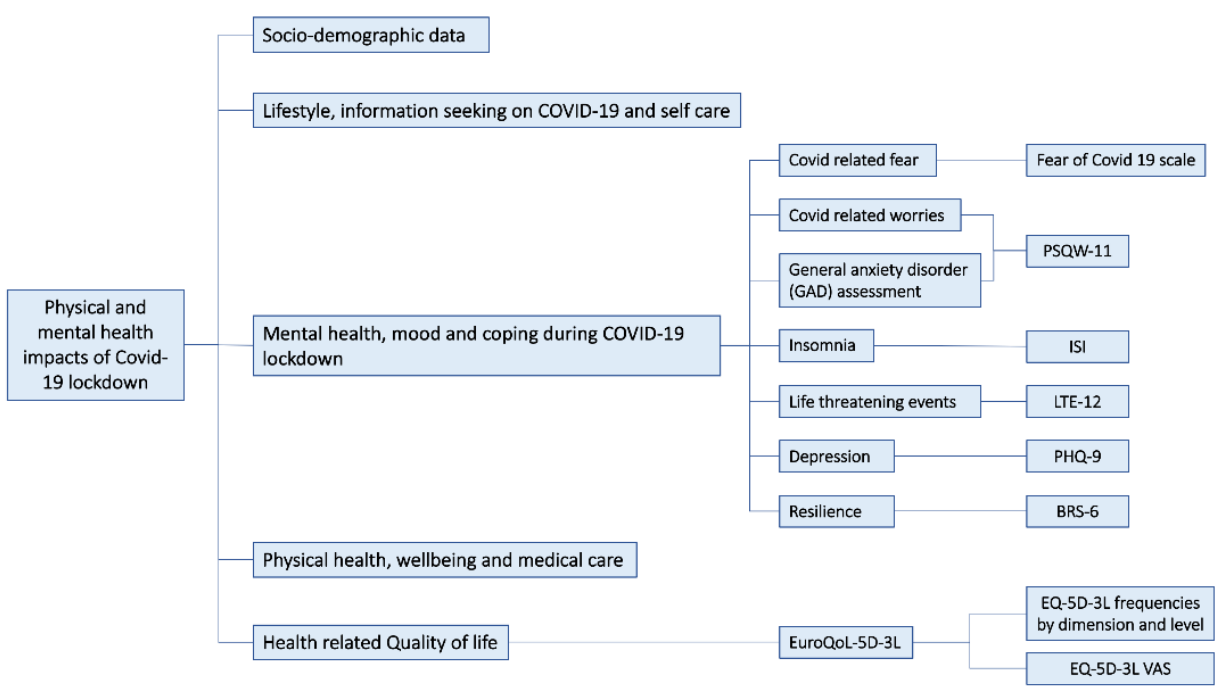

Fig. 1. Impact of COVID-19 lockdown on physical and mental health. Study diagram. PSWQ-11: Spanish abbreviated version of the Penn State Worry Questionnaire (PSWQ); ISI: insomnia severity index; LTE-12: list of threatening experiences (12 categories); PHQ-9: patient health questionnaire 9; BRS-6: brief resilience scale; EQ.5D-3L VAS: EuroQol-5D-3L visual analogue scale.

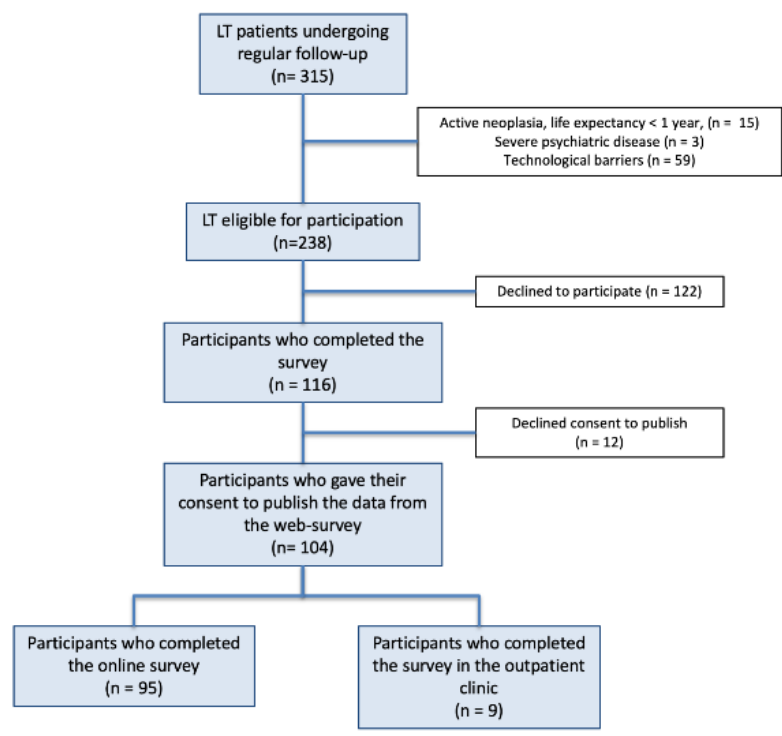


Fig. 2. Flow-chart of the study.

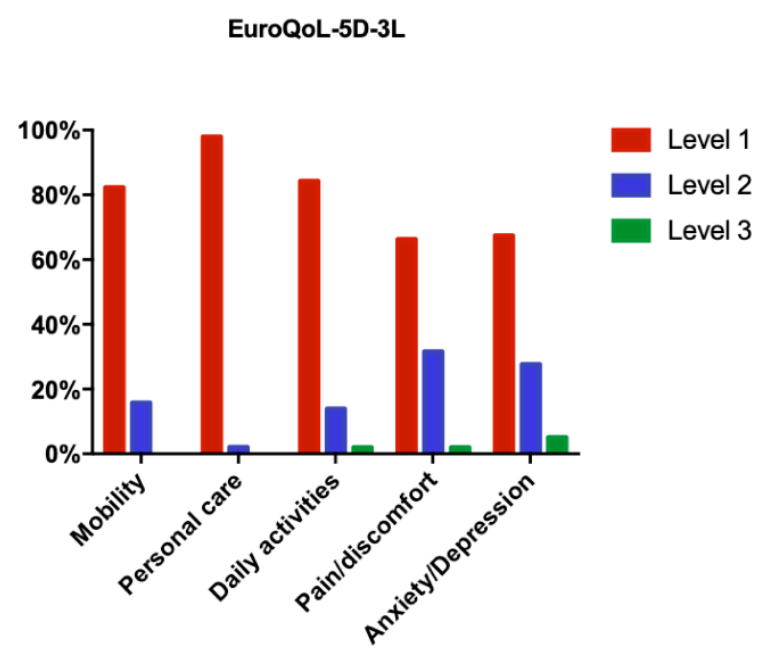

Fig. 3. Health-related quality of life (EuroQoL-5D-3L). Descriptive evaluation of each of the five dimensions of the EuroQoL-5D-3L in levels. Level 1: absence of problems; Level 2: some degree of problems or moderate feeling; Level 3: impossibility of doing different actions or severe discomfort. 